\title{
V-I Meter Based Autoswitch
}

\author{
Avanti Bhandarkar ${ }^{1}$, Saikat Banerjee ${ }^{2}$ \\ ${ }^{I}$ Department of Electronics and Telecommunication Engineering, G. H. Raisoni College of Engineering, \\ Nagpur, India \\ ${ }^{2}$ Department of Electronics Engineering, G. H. Raisoni College of Engineering, Nagpur, India
}

\begin{abstract}
In a country like India, which largely depends on rainfall, many a times due to weather changes, the total rainfall in a particular area may be either insufficient, or ill-timed. In order to get the maximum yield, it is essential to supply the optimum quantity of water, and maintain correct timing of water. Also, the farmer is over burdened by the pressure of turning ON and OFF the water motor at correct intervals of time. This problem can be reduced with the help of an Autoswitch. This project is primarily designed to measure the voltage \& current of single phase AC motors according to the limit set for the required motor specifications with additional circuitry to protect motor from over voltage, over current and dry run state. If the motor receives lot of current or voltage suddenly, the motor might get damaged. Hence, the circuit checks whether the input power is below the maximum power. In any case when a parameter exceeds the maximum operating limit, the circuit is automatically switched off to avoid any damage to the motor.
\end{abstract}

Keywords: Autoswitch, V-I meter, microcontroller, single phase motor, AC motors

\section{Introduction}

Voltage and Current measurement are essential parts of engineering and science. Instruments that measure voltage and currents are called voltmeter and ammeter respectively. This Autoswitch project is designed to measure the voltage \& current of three phase AC motors according to the limit set for the required motor specifications with additional circuitry to protect motor from over voltage, over current and dry run state. These motors typically tolerate variations in utilization voltage, power quality professionals continue to spend a great deal of time answering questions about proper utilization voltage for a given motor. While plant personnel can operate the motor with variations in the nominal voltage, they must understand all potential impacts on the motor and the supported process. The voltage quality factors that create the most serious problems and confusion in the field include nominal utilization voltage that does not match the motor nameplate, proper voltage sag ride-through protection for the motor control circuitry, and phase-to-phase voltage imbalance. With these factors in mind, we can formulate a systematic approach to investigate and resolve potential power quality problems.

\subsection{Previous Work}

In Autoswitch circuit the fundamental function is that the system trips and protects instantly at improper current sensing. Dry running is dangerous for submersible pumps. Motors of submersible pumps are designed for running under water. They use water as a heat-transfer medium. In case the water level goes down and the pump runs dry, the motor gets overheated and burns out. Due to such Dry running the bearing temperature also increases, damaging the bearing and the surrounding portion of the pump.

By using the ports of microcontroller we control the starter of the motor. Then interfacing the switch buttons to the port, by using these switch buttons we give the ON and OFF time to the motor. According to the availability of water in the bore wells we provide the timing. This is very useful for farmers. The farmers do not have to wait for ON and OFF the motors. If there is interrupt of electricity then farmer does not need to manually turn on the motor.

A few more methods were incorporated which considered the different factors for stable tripping in the system which include:

-When the system is first switched on, it waits for 30 seconds to make sure the power source is stable and starts monitoring.

-By switching ON or OFF of the relays, the microcontroller also turn on LEDs and the color of LED, being lit $\mathrm{ON}$, indicates which the three phases is ON or OFF.

-Under the control of the program written in the microcontroller's memory, the microcontroller turns either Red or Green LEDs and turns the three relays ON or OFF. 


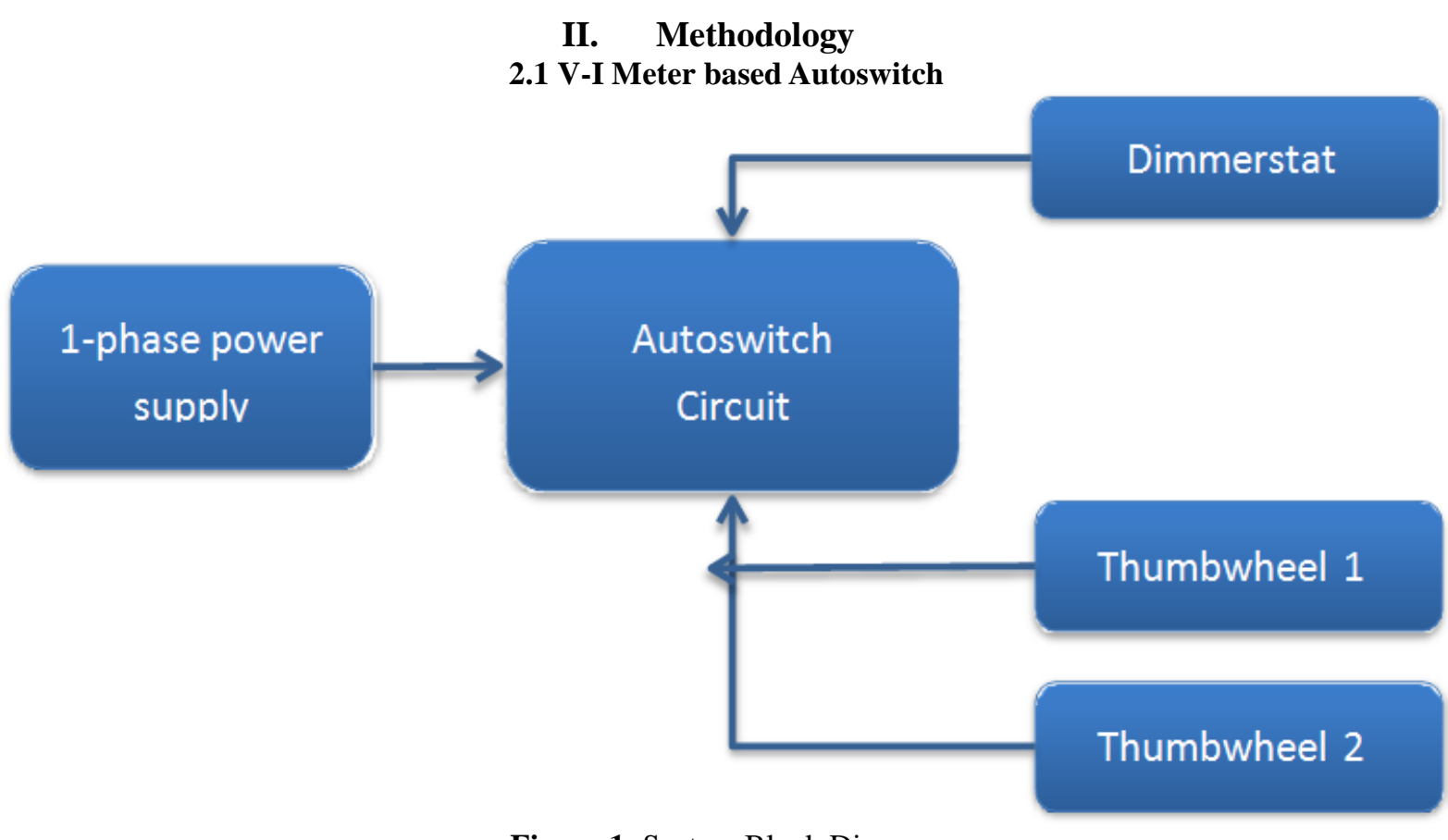

Figure 1: System Block Diagram

The block diagram comprises of four major equipments: that are single phase power supply, Autoswitch circuit, Dimmerstat and Thumbwheel. The process involves controlling the voltage and current supply that will eventually be given to the external motor. The tripping process for both voltage and current rating is done using the Autoswitch circuit.

\subsubsection{BLOCK 1 - Power Supply}

The first block is of single phase power supply which is a common method of alternating-current electric power generation, transmission, and distribution. It is also used to power large motors and other heavy loads. This circuit requires a heavy load so as to verify the current and voltage rating required to Autoswitch according to the set limits. Alternatively, a single phase power can be converted into a three phase by shifting its phase with an external circuit to produce a 3 phase power supply to the Autoswitch circuit. For testing purposes a single phase power supply is used in which a parallel connection of halogens and bulb are connected which can enable to vary the load so that voltage and current could be tested for nominal rating according to the motor's specification. Switching off one at a time to reduce the load and simultaneously measuring the adjacent voltage and current ratings can be done in this parallel combination.

\subsubsection{BLOCK 2 - Autoswitch Circuit}

The Autoswitch circuit has a function of determining whether the input voltage is greater than the required voltage or the input current is greater than dry run current, as these results of being greater than the nominal might lead to tripping off the circuit. The circuit uses PIC microcontroller for programming and debugging purpose so that the 7 segment and the led display indicate the user the current state of the circuit. This circuit comprises three LED which are used for indication i.e the first one is used for voltage reading being shown at the three serially arranged 7 segment display within 5 second of delay given to the microcontroller the second led will glow displaying the current reading on the 7 segment display, the third one is the indicator to display whether the circuit will trip or not, a value greater than nominal rating will lead to tripping of the circuit.

\subsubsection{BLOCK 3\&4 - Dimmerstat \& Thumbwheel Switches}

While testing, multiple observations would lead to a conclusive result that would in turn ensure the circuit's reliability. The equipment used in varying the voltage is Dimmerstat, an automatic voltage adjustment that can be used as automatic voltage regulator, to maintain a steady voltage at the customers' service during a wide range of line and load conditions. For current rating, two thumbwheel switches are used as the two digits for limiting the current value according to the requirement. A thumbwheel switch is a multi-position rotary switch. It contains a sprocket that can go forward or backward. As you can imagine from the name, you will be able to use a thumb, or a finger, to move the sprocket each way. This process helps in calculating the output power so that it can be compared with the maximum power. The continuous working can be set if and when all 
the condition for input voltage greater than the cut-off voltage set, actual current drawn by motor is greater than dry run current and the calculated power is less than max power required are satisfied or else the motor will stop.

\subsection{Flowchart}

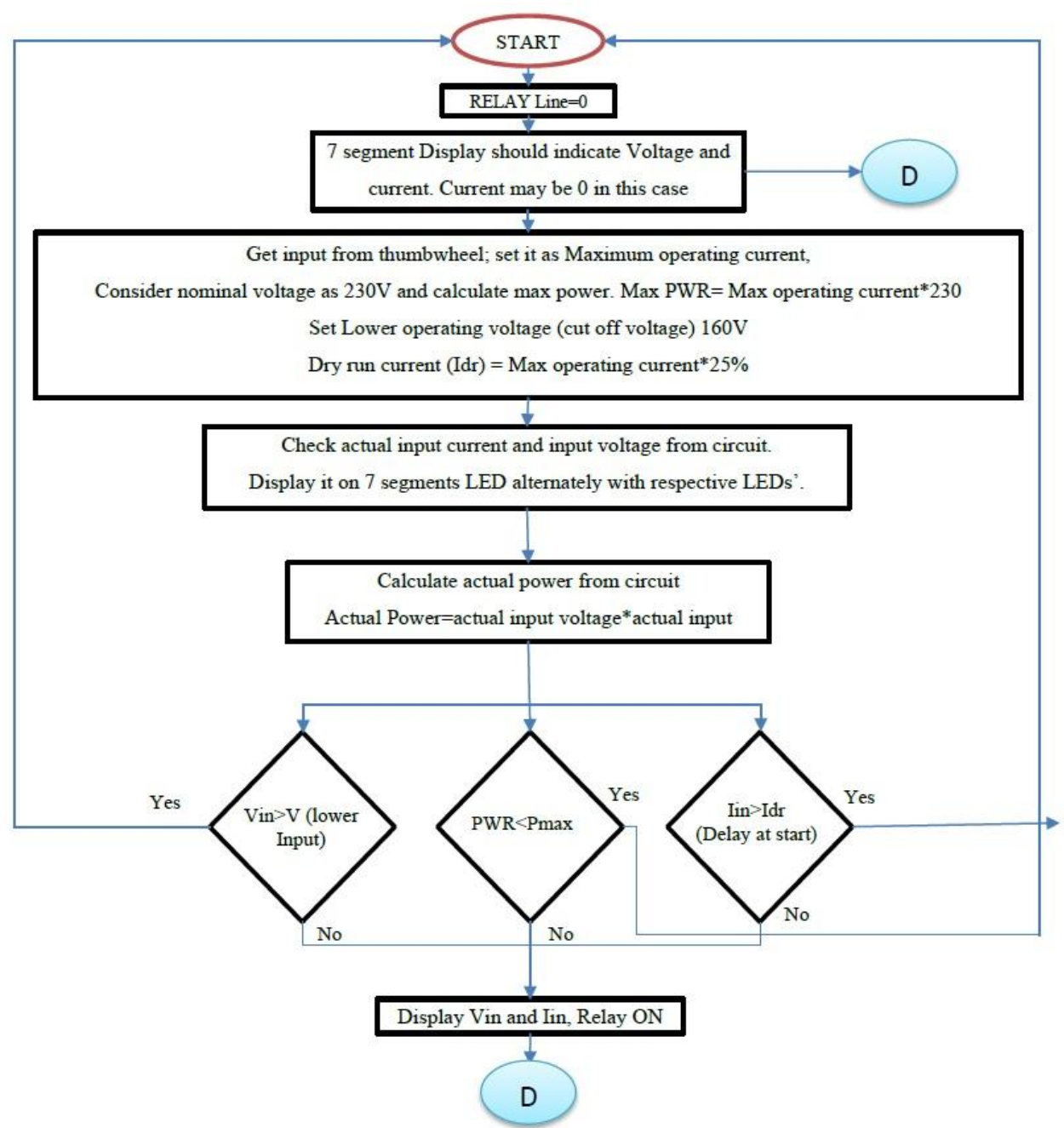

Figure 2: Flowchart

\subsection{Experimental Setup}

\section{Design And Implementation}

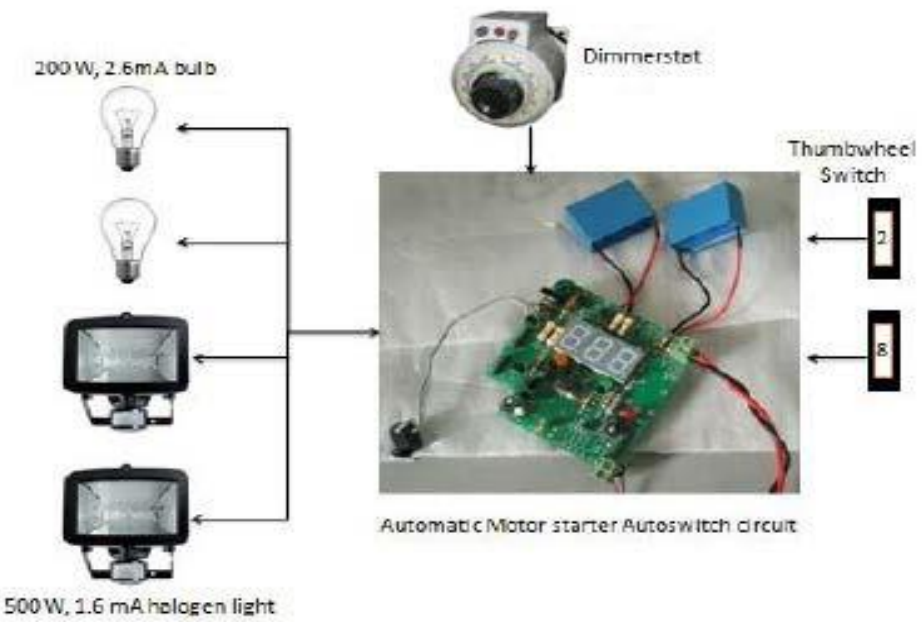

Figure 3: Experimental Setup 
The testing assembly essentially consists of the following:

- $\quad$-I meter based autoswitch circuit.

- 200W, 2.6mA Bulb - 2 No. 500W,

- $\quad 1.6 \mathrm{~mA}$ Halogen Light -2 No.

- Dimmerstat - 1 No.

- Thumbwheel switch -2 No.

\subsection{V-I Testing}

For the testing purpose, we have connected 2 halogen lights and 2 bulbs. All the lights have been connected in parallel with each other to produce the current and voltage load on the circuit. By knowing the current and voltage values, power can be calculated. The voltage and current readings are being displayed on the 7 segment display at an interval of $5 \mathrm{sec}$ delay that has been set in the programming. The voltage and current are also noted using a digital multimeter.

The voltage and current readings of the tests conducted on the circuit are as given below.

\begin{tabular}{|c|c|c|}
\hline & Volta & adings \\
\hline & Digital Multi-Meter & 7-Segment Display \\
\hline & 0 & 0 \\
\hline & 50.3 & 55.3 \\
\hline & 100.4 & 101 \\
\hline & 180.4 & 178 \\
\hline & 220 & 216 \\
\hline & 234 & 234 \\
\hline & Curre & adings \\
\hline & Digital Multi-Meter & 7-Segment Display \\
\hline & 0 & 0 \\
\hline & 4.1 & 4.8 \\
\hline & 5.38 & 5.53 \\
\hline & 6.7 & 6.32 \\
\hline & 7.51 & 6.9 \\
\hline No Load Condition & 1 & 1 \\
\hline
\end{tabular}

Table 1. V-I readings using digital multimeter and 7 segment display

\subsection{Equations}

Maximum Operating Power = Max Current x Max Voltage Dry Run Current $(\mathrm{Idr})=25 \%$ (Maximum operating current)

Actual Power $=$ Actual Input Voltage $\mathrm{x}$ Actual Input Current

\section{Results}

We have set the maximum current limit of $8 \mathrm{~A}$ from the thumbwheel switch

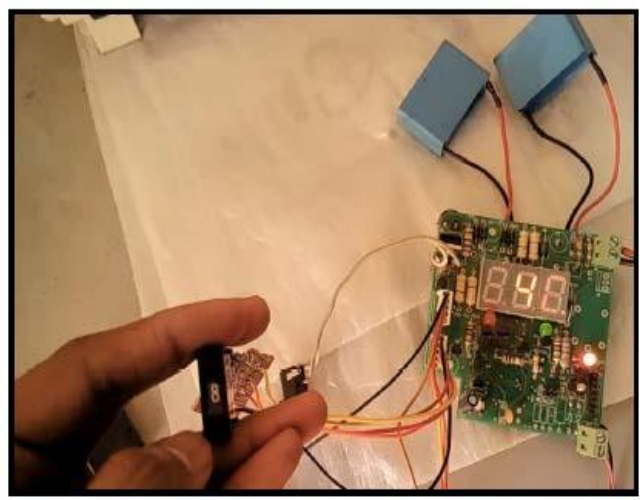

Figure 4: Thumbwheel Switch set at $8 \mathrm{~A}$ as maximum operating current 


\section{CASE 1: With no load on the circuit}

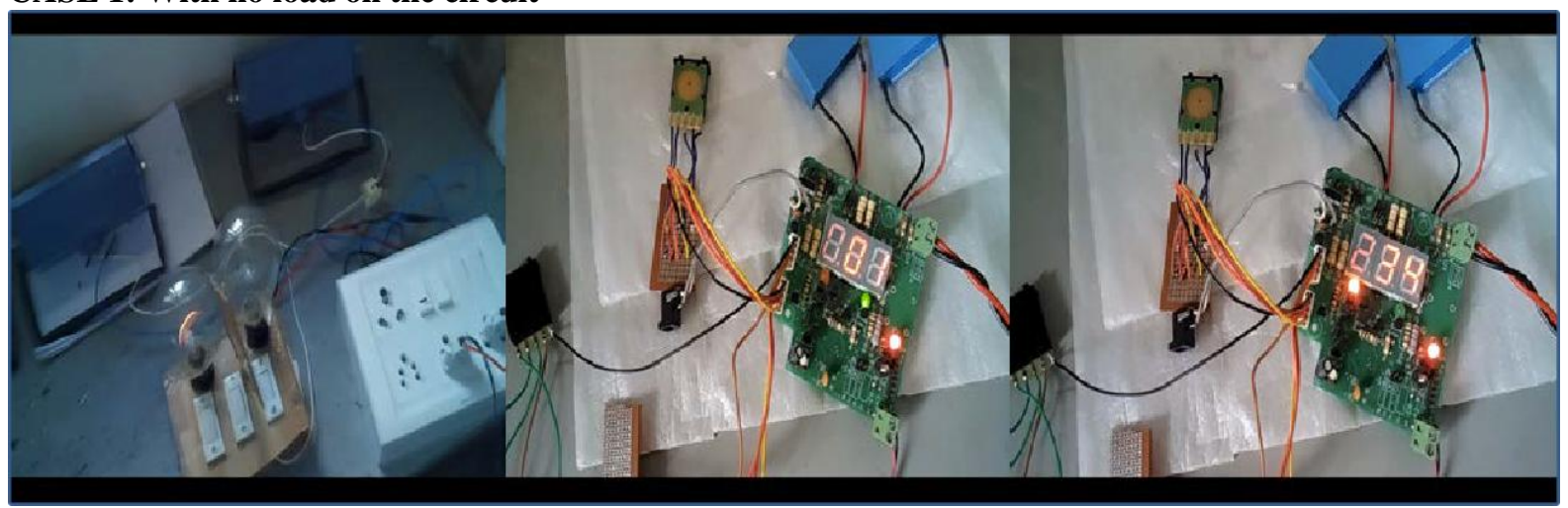

Figure 5: Current (Left) and Voltage (Right) reading on applying no load to the circuit

Power $1=$ Current $1 \times$ Voltage 1

Power1 = $1 \mathrm{~A} \times 234 \mathrm{v}=234 \mathrm{~W}$

\section{CASE 2: 1 Halogen light and 1 Bulb is ON}

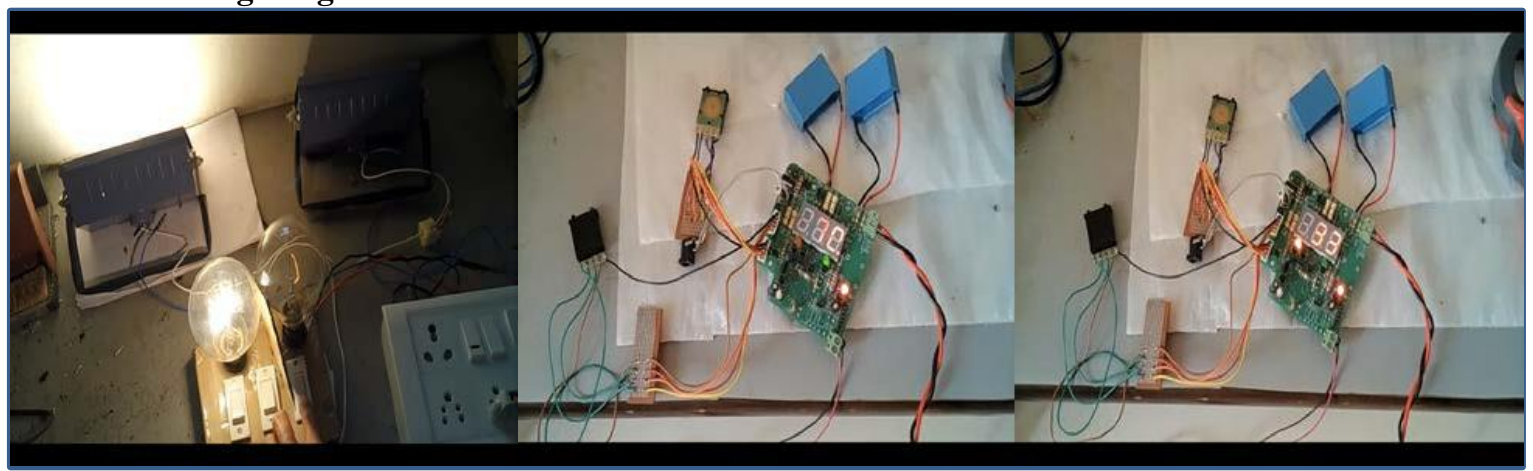

Figure 6: Current (Left) and Voltage (Right) reading when 1 halogen light and 1 bulb is ON

Power2 $=$ Current $2 \times$ Voltage 2

POWER2 $=4.1 \mathrm{~A} \times 50.3 \mathrm{~V}=206.23 \mathrm{~W}$

\section{CASE 3: 2 Halogen Lights and 1 Bulb are OFF}

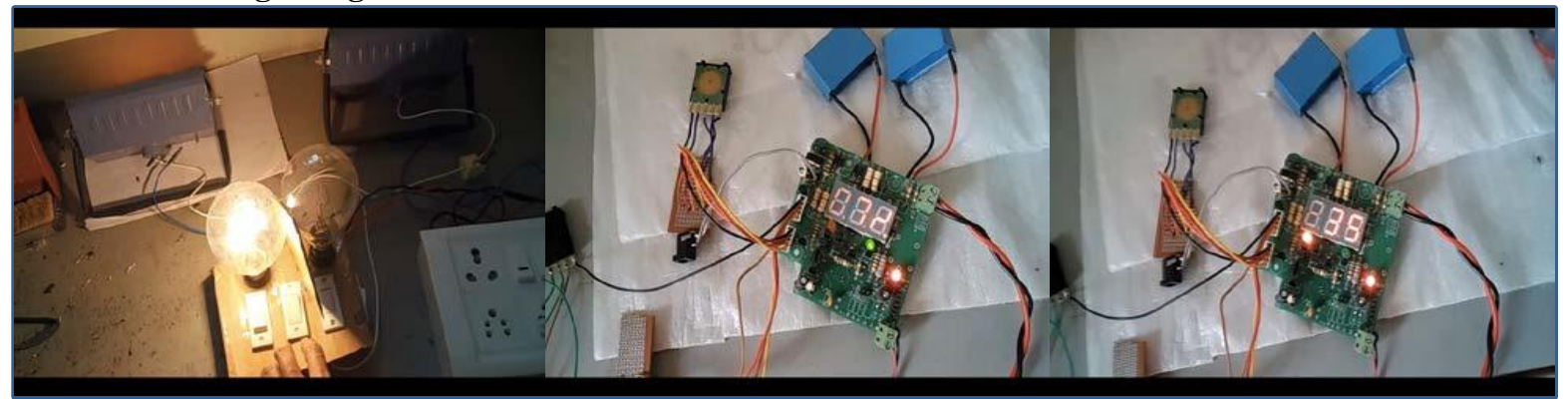

Figure 7: Current (Left) and Voltage (Right) reading when 2 halogen lights and 1 bulb are ON Power3 $=$ Current $3 \times$ Voltage 3

Power $3=5.38 \mathrm{~A} \times 100.4 \mathrm{~V}=540.15 \mathrm{~W}$ 


\section{CASE 4: 2 Bulbs and 1 Halogen light is ON}

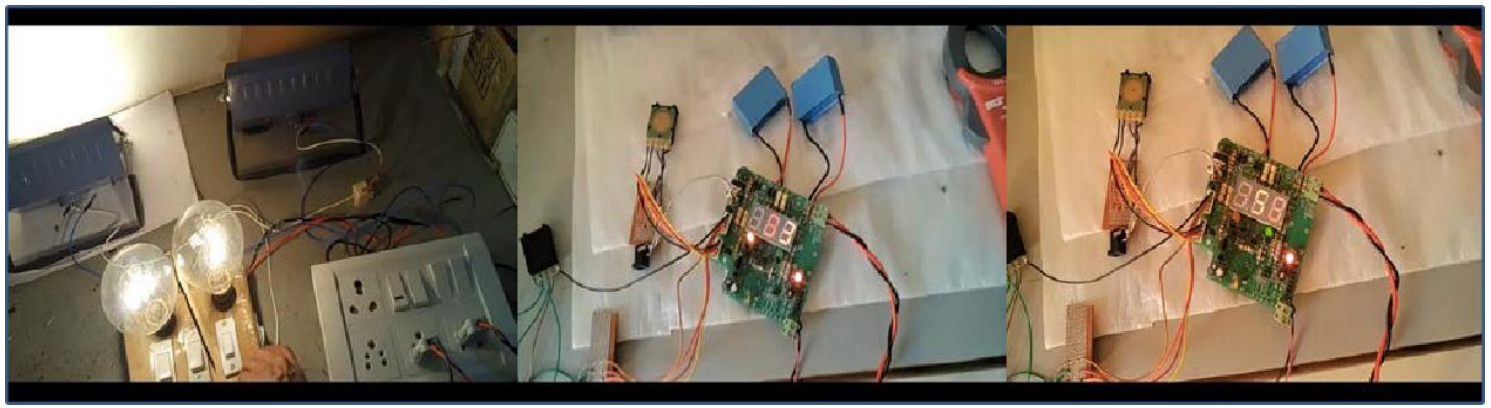

Figure 8: Current (Left) and Voltage (Right) reading when 2 halogen lights and 1 bulb are ON

Power4 = Current4 $\times$ Voltage 4

Power4 = 6.7 A x 180.4 V = 1208.68 W

\section{CASE 5: All the lights are ON}

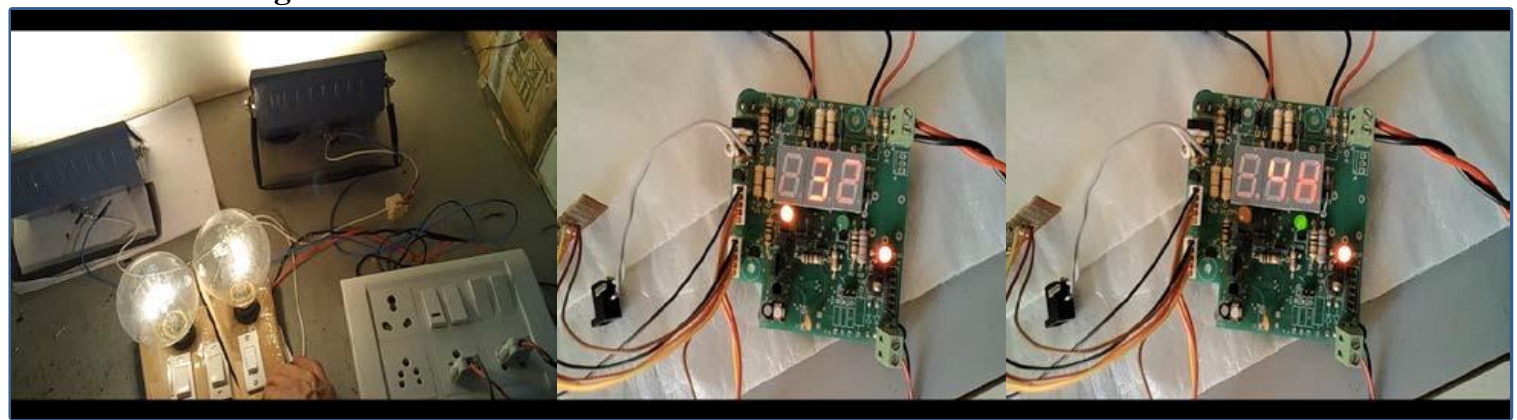

Figure 9: Current (Right) and Voltage (Left) reading when all the lights are ON i.e. Full Load condition Power5 = Current5 x Voltage5

Power5 $=7.51 \mathrm{~A}$ x $220 \mathrm{~V}=1652.2 \mathrm{~W}$

\section{Conclusion}

Thus, the Autoswitch project is designed to measure the voltage \& current of single phase AC motors according to the limit set for the required motor specifications with additional circuitry to protect motor from over voltage, over current and dry run state. Hence, the circuit checks whether the input power is below the maximum power. In case when a parameter exceeds the maximum operating limit, the circuit is automatically switched off to avoid any damage to the motor. Motor. The autoswitch project can be further interfaced with a GSM module to create a GSM based wireless remote data logger which can be used for real time online data acquisition, monitoring and control of remotely installed motor.

\section{Future Scope}

The Autoswitch project can be further interfaced with a GSM module to create a GSM based wireless remote data logger which can be used for real time online data acquisition, monitoring and control of remotely installed motor. SMS/GSM Remote Motor Controller Autoswitch is an intelligent device which can control and monitor electric motors, agriculture pump sets through mobile phone. This is a GSM based remote controller to switch ON and OFF pump sets or any electric motor from remote location. This SMS/GSM remote controller helps the farmer to handle agricultural pump sets easily. Farmer can set running time of pump set after it gets ON. It also helps the farmers to save life from snake bite in night time, saves water, time and electricity. One SIM Card is required for its operation. This data logger will use a SIM card from any GSM service provider with server or any mobile phone by SMS or talks on phone in required language. The system will be installed and connected to the motor after which the system will continuously monitor the activity of the motor at site and will send all the data to the server or any mobile phone by SMS on real time basis.

\section{Journal Papers:}

\section{References}

[1]. Atser A. Roy, Gesa, F. Newton \& Aondoakaa.I.Solomon, "Design and Implementation of a 3-Phase Automatic Power Change-over Switch", American Journal of Engineering Research (AJER) e-ISSN: 2320-0847 p-ISSN: 2320-0936 Volume-3, Issue-9, pp-07-14.

[2]. Aashish Joshi, Ashish Mali, Avdhut Jadhav and Nagesh Chavan, "Microcontroller Based System for Bore-Well 3-Phase Motor to Avoid Dry Running”, IJCEM International Journal of Computational Engineering \& Management, Vol. 17 Issue 3, May 2014. 
[3]. "Three Phase Motor Control using GSM", Prof. R.R Jadhav, Prathmesh P Pandit, Shubham D. Pal and Vineet H. Risbud,Electronics Department, Coem, International Journal Of Innovative Research In Electrical, Electronics, Instrumentation And Control Engineering, Vol. 3, Issue 5, May 2015.

[4]. Agbo D. O., Kureve D. T, Shittu D. H, "Implementation Of An Automatic Induction Motor Starter With Delay Using Microcontroller", International Journal Of Scientific \& Technology Research Volume 3, ISSUE 5, May 2014 ISSN 2277-8616.

[5]. Rahul R.Petkar, Pallavi S. Shinde, Pallavi B. Bachche, Dhiraj G. Kamble, Sonal C.Desai, "Auto Control for Three Phase Induction Motor", International Journal Of Innovations In Engineering Research And Technology [IJIERT] , Volume 2, Issue: 4 Apr.-2015, ISSN: 2394-3696.

[6]. Wani Suraj R, Ghaywat Vivek V, Naik Akshay D, Mandlik Sachin B, "IVR System for three phase motor protection, Control and Alert system using GSM", International Journal Of Engineering And Computer Science ,Volume 4, Issue: 2 February 2015, ISSN:2319- 7242. 